\title{
ANALISIS PERBANDINGAN TINGKAT TEKANAN BUNYI TERHADAP SISTEM PEMBANGKIT SUARA AKUSTIK DENGAN EFEK SURROUND DAN TANPA EFEK SURROUND
}

\author{
Yusuf Nugraha \\ Program Studi Teknik Informatika, Universitas Indraprasta PGRI \\ inux007@yahoo.com
}

Submitted November 10, 2020; Revised November 22, 2020; Accepted December 4, 2020

\begin{abstract}
Abstrak
Penelitian ini bertujuan untuk mengetahui perbandingan tingkat tekanan bunyi yang dihasilkan oleh sistem pembangkit suara akustik dengan efek surround dengan tanpa efek surround. Sistem pembangkit suara akustik dengan efek surround dirancang dan dibuat sebagai sistem tata suara yang menghasilkan efek surround dimana suara yang dihasilkan dibagi dan disalurkan lebih dari dua atau banyak kanal (multi channel). Sistem tata suara ini terdiri dari empat bagian yaitu : front cannel, rear surround channel, extra rear channel dan subwoofer. Sistem ini mendapat input dari VCD berupa sinyal R dan L masuk ke IC AN7397K kemudian keluar melalui empat output kanal. Masing-masing output kanal dihubungkan dengan power amplifier stereo dan mono 150 watt. Dari hasil penelitian dengan uji statistik menggunakan distribusi t menunjukkan bahwa terjadi perbedaan tingkat tekanan bunyi (SPL) antara sistem pembangkit suara akustik dengan efek surround dengan tanpa efek surround pada jarak 1 meter sampai dengan 10 meter, dimana diperoleh nilai tingkat tekanan bunyi dengan sistem pembangkit suara akustik dengan efek surround lebih tinggi dibandingkan tingkat tekanan bunyi tanpa efek surround.
\end{abstract}

Kata kunci : Tingkat tekanan bunyi (SPL), Sistem pembangkit suara, Efek surround, IC AN7397K

\begin{abstract}
This study aims to determine the comparison of the sound pressure level produced by an acoustic sound generator system with surround effects without surround effects. Acoustic sound generating system with surround effects is designed and made as a sound system that produces a surround effect where the resulting sound is divided and distributed over two or many channels (multi channel). This sound system consists of four parts, namely: front cannel, rear surround channel, extra rear channel and subwoofer. This system gets input from the VCD in the form of $R$ and L signals into the AN7397K IC then comes out through four output channels. Each output channel is connected to a 150 watt stereo and mono power amplifier. From the results of research with statistical tests using the $t$ distribution shows that there is a difference in sound pressure level (SPL) between acoustic sound generating systems with surround effects without surround effects at a distance of 1 meter to 10 meters, where the value of the sound pressure level with a sound generator system is obtained. acoustics with a surround effect higher than the sound pressure level without a surround effect.
\end{abstract}

Keywords: Sound pressure level (SPL), Sound generating system, Surround effects, IC AN7397K

\section{PENDAHULUAN}

Seiring dengan perkembangan zaman, kemajuan teknologi sangat berkembang dengan pesat terutama di bidang elektronika. Perusahaan teknologi mulai banyak mengembangkan suatu perangkat yang dapat mendukung kinerja manusia. Teknologi elektronik seakan tidak hanya tertuju pada satu bidang saja namun pada semua bidang. Salah satunya adalah pengembangan teknologi audio. Teknologi tata suara (audio) ini dikembangkan untuk mendukung industri musik.

Pada tahun 1970-an, perangkat audio masih menggunakan sistem mono yang hanya memiliki satu saluran suara. Dalam 
waktu yang cukup lama, sistem mono disempurnakan dengan sebuah sistem saluran suara yaitu sistem stereo. Sistem stereo merupakan sistem tata suara dimana suara yang dihasilkan dibagi dan disalurkan melalui dua kanal secara terpisah. Keunggulan sistem stereo adalah dalam hal respon frekuensi. Efek yang ditimbulkan oleh sistem stereo membuat respon frekuensi cenderung merata sehingga suara yang dihasilkan menjadi lebih tinggi.

Pada tahun 1990-an, perusahaan elektronik mulai mengadopsi teknologi surround yang merupakan pengembangan teknologi audio yang menghasil tata suara yang lebih baik dibandingkan sistem tata suara stereo, dimana suara yang dihasilkan dibagi dan disalurkan lebih dari dua atau banyak kanal (multi-channel). Keunggulan sistem surround adalah pada penciptaan efek suara yang dihasilkan mendekati nyata/realisme.

Beberapa penelitian sebelumnya telah merancang sistem audio dengan mengadopsi teknologi efek surround dengan multi-channel antara lain oleh [7] /1 yang merancang sistem pembangkit efek surround dengan IC Bucket Brigade Device (BBD) MN 3008 yang memiliki kemampuan untuk menghasilkan efek reverberasi dengan saluran tunda sebanyak 2048 tingkat tunda dengan waktu tunda sampai 102,4 milidetik. Dengan menggunakan sistem ini, dapat dibentuk suara reverberasi dengan waktu tunda yang dapat diatur dari 10,5 milidetik - 15,5 milidetik sehingga suara yang dihasilkan lebih lebar dan lebih hidup dan seakanakan pendengar berada pada ruangan yang luas [7].

Suatu sistem audio surround dirancang dengan processor berbasis IC UPC1891ACY yang mempunyai rangkaian delay untuk memberikan time delay sekitar 10 milidetik antara speaker depan dan speaker belakang, sehingga menghasilkan efek surround seperti pada home theater didalam ruangan dan sistem kerja audio surround processor ini bekerja memberikan efek pada input audio sehingga menghasilkan output yang berbeda - beda dengan range frekuensi $4 \mathrm{kHz}$ sampai dengan $400 \mathrm{kHz}$ [3].

Dalam penelitian [8] menyatakan bahwa pada sistem MPEG surround dengan codec terbaru yang telah distandardisasi secara internasional masih menggunakan open loop yang tidak memiliki kemampuan untuk meminimalkan error, sedangkan hasil análisis kinerja perancangannya dengan pengkodean audio multichannel dengan metode closed loop pada MPEG Surround dapat meminimalisasi terjadinya error pada kompresi audio multichannel.

Saat ini, sistem tata suara (audio) yang ada di pasaran sudah banyak yang memiliki fasilitas surround sound, namun efek surround yang dihasilkan pada jarak yang cukup jauh menjadi hilang. Hal ini disebabkan karena tata letak speaker yang kurang tepat dan ruang akustik yang kurang baik. Parameter fisis akustik yang umumnya digunakan untuk menggambarkan perilaku suara yaitu intensitas bunyi.

Intensitas bunyi didefinisikan sebagai energi yang dipindahkan per satuan luas per satuan waktu atau daya per satuan luas yang tegak lurus pada arah rambat gelombang [4][5]. Tingkat intensitas bunyi adalah logaritma perbandingan antara intensitas bunyi I dengan nilai intensitas ambang bunyi $\mathrm{I}_{0}$.

Tingkat tekanan bunyi (SPL) merupakan algoritma perbandingan antara tekanan bunyi $\mathrm{P}$ dengan harga tekanan ambang bunyi Po [4][5]. Tingkat tekanan bunyi diukur dalam skala algoritma yang disebut skala decibel (dB). Satuan skala decibel adalah penyimpangan terkecil dalam tekanan bunyi yang dapat dideteksi oleh telinga manusia. 
Tingkat tekanan bunyi minimum yang mampu membangkitkan sensasi pendengaran di telinga manusia adalah ambang kemampuan didengar. Bila tekanan bunyi ditambah dan bunyi menjadi lebih keras, akhirnya mencapai suatu tingkat dimana sensasi pendengaran menjadi tidak nyaman.

Manusia mendengar bunyi saat gelombang bunyi yaitu getaran udara atau medium lain sampai ke gendang telinga manusia. Batas frekuensi bunyi yang dapat didengar oleh telinga manusia antara $20 \mathrm{~Hz}$ sampai dengan $20 \mathrm{kHz}$ pada amplitudo umum dengan berbagai variasi dalam kurva respon. Suara diatas $20 \mathrm{kHz}$ disebut ultrasonik dan dibawah $20 \mathrm{~Hz}$ disebut infrasonik [9].

Tingkat tekanan bunyi minimum yang merangsang telinga sampai suatu keadaan dimana rasa tidak nyaman menyebabkan rasa sakit tertentu disebut ambang rasa sakit. Antara kemampuan didengar dan rasa sakit, tekanan bertambah sejuta kali. Ini menunjukkan jangkauan tekanan bunyi yang ditanggapi telinga sangat lebar.

Berdasarkan latar belakang tersebut, penelitian ini mencoba merancang suatu sistem tata suara (audio) yaitu sistem pembangkit suara akustik dengan efek surround. Sistem pembangkit suara akustik dengan efek surround ini memiliki 4 kanal speaker yang terdiri dari 2 main speaker, 2 rear speaker, 1 extra rear speaker dan 1 subwoofer. Untuk mendapatkan daya yang lebih besar, maka masing-masing kanal akan dilengkapi dengan amplifier.

Sistem pembangkit suara akustik dengan efek surround dirancang dari rangkaian opamp. Penguat operasional atau op-amp adalah penguat diferensial dengan dua masukan dan satu keluaran yang mempunyai penguat tegangan yang sangat tinggi. Dengan penguat tegangan yang sangat tinggi, maka penguat operasional dengan rangkaian pembalik lebih banyak digunakan dibandingkan rangkaian tak pembalik.

Dari sistem pembangkit suara akustik dengan efek surround ini akan diuji untuk mengetahui perbandingan tingkat tekanan bunyi (SPL) yang dihasilkan oleh sistem pembangkit suara akustik dengan efek surround dengan tanpa efek surround.

\section{METODE PENELITIAN}

\section{Jenis dan Sumber Data}

Jenis data yang digunakan dalam penelitian ini adalah data primer, yaitu data pengamatan. Data yang diperoleh berasal dari hasil pengukuran tingkat tekanan bunyi (SPL) yang dihasilkan antara sistem pembangkit suara akustik dengan efek surround dengan tanpa efek surround. Penelitian ini dilakukan di laboratorium Elektronika Jurusan Fisika, FMIPA dan Auditoriun Widya Sabha Universitas Udayana, Kampus Bukit Jimbaran, Bali.

\section{Periode Pengamatan}

Pengukuran tingkat tekanan bunyi (SPL) menggunakan alat ukur sound level meter dilakukan dari jarak 1 meter sampai dengan 10 meter. Setiap jarak 1 meter dilakukan pengukuran sebanyak 31 kali setiap 10 detik.

\section{Model Analisis Penelitian}

Untuk memudahkan pengertian dan menghindari kesalahan persepsi dari masing-masing variabel penelitian, maka perlu didefinisikan variabel-variabel yang dipergunakan dalam penelitian ini disertai cara pengukurannya.

Berikut ini dijelaskan definisi dari masingmasing variabel penelitian disertai cara pengukurannya :

1. Perhitungan jumlah sampel tingkat tekanan bunyi dengan sistem pembangkit suara akustik dengan efek surround.

$$
\sum F=\left(F_{j, 1}+F_{j, 2}+F_{j, 3}\right)
$$


2. Perhitungan jumlah sampel tingkat tekanan bunyi tanpa efek surround.

$\sum H=\left(H_{j, 1}+H_{j, 2}+H_{j, 3}\right)$

3. Perhitungan rata-rata tingkat tekanan bunyi dengan sisten pembangkit suara akustik dengan efek surround.

$\overline{\mathrm{F}}=\frac{\sum \mathrm{F}}{\mathrm{n}}$

4. Perhitungan rata-rata tingkat tekanan bunyi tanpa efek surround.

$$
\overline{\mathrm{H}}=\frac{\sum \mathrm{H}}{\mathrm{n}}
$$

5. Perhitungan standar deviasi tingkat tekanan bunyi dengan sistem pembangkit suara akustik dengan efek surround.

$S_{F}=\sqrt{\frac{\sum\left(F_{j}-\bar{F}\right)^{2}}{n-1}}$

6. Perhitungan standar deviasi tingkat tekanan bunyi tanpa efek surround.

$$
\mathrm{S}_{\mathrm{H}}=\sqrt{\frac{\sum\left(\mathrm{H}_{\mathrm{j}}-\overline{\mathrm{H}}\right)^{2}}{\mathrm{n}-1}}
$$

7. Perhitungan standar probabilitas.

$$
S_{P}=\sqrt{\frac{\left(n_{F}-1\right) S_{F}^{2}+\left(n_{2}-1\right) S_{H}^{2}}{n_{1}+n_{2}-2}}
$$

8. Perhitungan distribusi t.

$$
t_{\text {hit }}=\frac{\overline{\mathrm{F}}-\overline{\mathrm{H}}}{\mathrm{S}_{\mathrm{P}} \sqrt{\frac{1}{\mathrm{n}_{\mathrm{F}}}+\frac{1}{\mathrm{n}_{\mathrm{H}}}}}
$$

Penelitian ini menggunakan pengujian distribusi $t$ dengan hipotesis sebagai berikut :

$$
\begin{aligned}
\mathrm{H}_{0}: \mathrm{F}=\mathrm{H} & \begin{array}{l}
\text { (Tidak ada perbedaan antara } \\
\text { sistem pembangkit suara } \\
\text { akustik dengan efek } \\
\text { surround dan tanpa efek } \\
\text { surround) }
\end{array} \\
\mathrm{H}_{1}: \mathrm{F} \neq \mathrm{H} & \begin{array}{l}
\text { (Ada perbedaan antara sistem } \\
\text { pembangkit suara akustik } \\
\text { dengan efek surround dan } \\
\text { tanpa efek surround) }
\end{array}
\end{aligned}
$$

Jika nilai t statistik lebih besar dari nilai $t$ tabel, maka cukup bukti bagi kita untuk melakukan penolakan terhadap $\mathrm{H}_{0}$ sehingga $\mathrm{H}_{1}$ diterima. Sebaliknya, jika nilai $\mathrm{t}$ statistik kurang dari nilai $\mathrm{t}$ tabel, maka $\mathrm{H}_{0}$ diterima.

\section{HASIL DAN PEMBAHASAN}

\section{Skema Blok Sistem Pembangkit Suara}

Akustik dengan Efek Surround

Perancangan sistem pembangkit suara akustik dengan efek surround dapat dibuat dalam bentuk diagram blok seperti ditunjukkan pada Gambar 1.

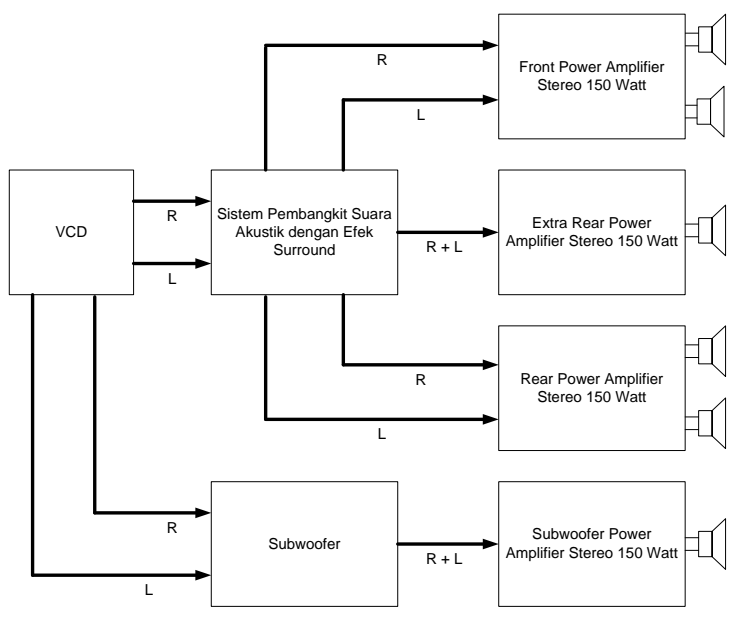

Sumber : Hasil Pengolahan Data

Gambar 1. Diagram Blok Sistem Pembangkit Suara Akustik dengan Efek Surround 
Kontruksi Sistem Pembangkit Suara Akustik Dengan Efek Surround

Pada dasarnya sistem pembangkit suara akustik dengan efek surround dibangun dari rangkaian op-amp dan filter. Op-amp yang biasanya digunakan sebagai penguat tegangan dalam sistem pembangkit suara akustik dengan efek surround lebih banyak digunakan sebagai filter-filter aktif. Filter dalam alat ini sangat berperan besar dalam menciptakan suatu suara akustik yang sangat jernih, tetapi di dalam prakteknya, hampir semua filter tidak presisi dalam melewatkan sinyal dengan frekuensi tertentu.

Sebuah op-amp yang baik untuk aplikasi ini adalah op-amp yang mempunyai bandwith lebar, rise time, slew rate dan settling time yang cepat. Selain op-amp dan filter aktif, masih ada bagian lain yang penting yaitu catu daya. Catu daya merupakan bagian yang berperan dalam menciptakan kesempurnaan suara akustik. Apabila catu dayanya tidak baik hanya menghasilkan noise yang akan masuk ke dalam jalur sinyal suara, sehingga suara akustik yang seharusnya jernih menjadi suara akustik dengan tambahan dengung (noise). Catu daya pada rangkaian ini menggunakan IC regulator yaitu IC 7809 dengan masukan input AC $3 \mathrm{~A}$.

Cara Kerja Sistem Pembangkit Akustik dengan Efek Surround

Rancangan sistem pembangkit suara akustik dengan efek surround terdiri dari 4 bagian yaitu : front channel, rear surround channel, extra rear channel dan subwoofer channel.

Front channel merupakan kanal yang meneruskan sinyal input $\mathrm{R}$ dan $\mathrm{L}$. sinyal input $\mathrm{R}$ dan $\mathrm{L}$ dari $\mathrm{VCD}$ dilewatkan pada IC AN7397K, sehingga sinyal ini dilewatkan tanpa merubah sinyal input $\mathrm{R}$ dan L tersebut. Output dari front channel kemudian dikuatkan dengan power amplifier stereo 150 watt.
Pada bagian extra rear channel, sinyal input dari VCD yaitu sinyal input $\mathrm{R}$ dan $\mathrm{L}$ dilewatkan pada sebuah IC AN7397K. Output dari extra rear channel yaitu sinyal $\mathrm{R}$ dan $\mathrm{L}$ yang diparalel dengan output rear channel dan menghasilkan satu sinyal kemudian dikuatkan dengan menggunakan power amplifier mono 150 watt.

Pada bagian rear channel dengan surround merupakan inti dari sistem pembangkit suara akustik dengan efek surround. Bagian inilah yang menghasilkan efek surround. Untuk menghasilkan efek surround digunakan IC AN7397K. Sinyal input $\mathrm{R}$ dan $\mathrm{L}$ dari $\mathrm{VCD}$ dilewatkan pada sebuah IC AN7397K kemudian dikuatkan dengan IC TDA2005 yang berfungsi sebagai sebagai rear power amplifier.

Bagian subwoofer merupakan penjumlahan input $\mathrm{R}$ dan $\mathrm{L}$ pada sebuah summing amplifier. Output dari summing amplifier dilewatkan pada sebuah IC YD4558 yang hanya melewatkan sinyal dengan frekuensi rendah kemudian dikuatkan dengan power amplifier mono 150 watt untuk menghasilkan suara bass yang bagus.

\section{Skema Blok Tanpa Efek Surround}

Perancangan tanpa efek surround dapat dibuat dalam bentuk diagram blok seperti ditunjukkan pada Gambar 2.

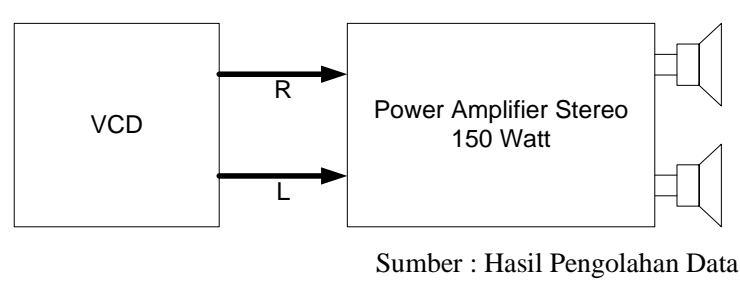

\section{Gambar 2. Diagram Blok Tanpa Efek Surround}

\section{Cara Kerja Tanpa Efek Surround}

Sinyal input R dan L dari VCD di Switching dalam keadaan off atau sinyal $\mathrm{R}$ dan $L$ tidak dilewatkan pada sistem pembangkit suara akustik dengan efek surround tetapi sinyal tersebut langsung 
melewati power amplifier stereo 150 watt dan output dihubungkan ke speaker.

\section{Hasil Pengujian Distribusi “T” Pada Jarak 1 Meter}

Penelitian ini mengambil satu contoh data pengamatan tingkat tekanan bunyi (SPL) antara sistem pembangkit suara akustik dengan efek surround dengan tanpa efek surround pada jarak 1 meter.

Tabel 1. Data Tingkat Tekanan Bunyi (SPL) Antara Sistem Pembangkit Suara Akustik Dengan Efek Surround dan Tanpa Efek Surround

\begin{tabular}{|c|c|c|c|c|c|c|}
\hline \multirow{2}{*}{\begin{tabular}{c|} 
Ulangan \\
$(\mathrm{n})$
\end{tabular}} & \multicolumn{2}{|c|}{ Perlakuan (a) } & \multirow{2}{*}{$F-\bar{F}$} & \multirow{2}{*}{$H-\bar{H}$} & \multirow{2}{*}{$(F-\bar{F})^{2}$} & \multirow{2}{*}{$(H-\bar{H})^{2}$} \\
\hline & $\mathrm{F}(\mathrm{dB})$ & $\mathrm{H}(\mathrm{dB})$ & & & & \\
\hline 1 & 83.6 & 78.6 & -5.1 & -5.3 & 25.6 & 27.7 \\
\hline 2 & 89.3 & 81.5 & 0.6 & -2.4 & 0.4 & 5.6 \\
\hline 3 & 83.2 & 80.2 & -5.5 & -3.7 & 29.8 & 13.4 \\
\hline 4 & 86.8 & 80.6 & -1.9 & -3.3 & 3.5 & 10.7 \\
\hline 5 & 88.1 & 83.3 & -0.6 & -0.6 & 0.3 & 0.3 \\
\hline 6 & 88.2 & 83.6 & -0.5 & -0.3 & 0.2 & 0.1 \\
\hline 7 & 87.9 & 84.4 & -0.8 & 0.5 & 0.6 & 0.3 \\
\hline 8 & 86.8 & 84.0 & -1.9 & 0.1 & 3.5 & 0.0 \\
\hline 9 & 81.6 & 83.8 & -7.1 & -0.1 & 49.9 & 0.0 \\
\hline 10 & 84.8 & \begin{tabular}{l|l}
84.2 \\
\end{tabular} & -3.9 & 0.3 & 14.9 & 0.1 \\
\hline 11 & 86.3 & 86.1 & -2.4 & 2.2 & 5.6 & 5.0 \\
\hline 12 & 87.6 & 87.6 & -1.1 & 3.7 & 1.1 & 14.0 \\
\hline 13 & 88.0 & 87.8 & -0.7 & 3.9 & 0.4 & 15.5 \\
\hline 14 & 91.2 & 87.1 & 2.5 & 3.2 & 6.4 & 10.5 \\
\hline 15 & 92.5 & 87.9 & 3.8 & 4.0 & 14.7 & 16.3 \\
\hline 16 & 92.5 & 85.4 & 3.8 & 1.5 & 14.7 & 2.4 \\
\hline 17 & 91.6 & 84.9 & 2.9 & 1.0 & 8.6 & 1.1 \\
\hline 18 & 93.8 & 83.8 & 5.1 & -0.1 & 26.4 & 0.0 \\
\hline 19 & 91.8 & 84.5 & 3.1 & 0.6 & 9.9 & 0.4 \\
\hline 20 & 90.6 & 82.7 & 1.9 & -1.2 & 3.8 & 1.4 \\
\hline 21 & 92.4 & 80.1 & 3.7 & -3.8 & 14.0 & 14.2 \\
\hline 22 & 97.0 & 79.2 & 8.3 & -4.7 & 69.5 & 21.8 \\
\hline 23 & 90.2 & 80.8 & 1.5 & -3.1 & 2.4 & 9.4 \\
\hline 24 & 89.7 & 84.4 & 1.0 & 0.5 & 1.1 & 0.3 \\
\hline 25 & 88.6 & 85.1 & -0.1 & 1.2 & 0.0 & 1.5 \\
\hline 26 & 87.9 & 86.8 & -0.8 & 2.9 & 0.6 & 8.6 \\
\hline 27 & 85.3 & 86.3 & -3.4 & 2.4 & 11.3 & 5.9 \\
\hline 28 & 83.2 & 82.2 & -5.5 & -1.7 & 29.8 & 2.8 \\
\hline 29 & 82.1 & 85.5 & -6.6 & 1.6 & 43.1 & 2.7 \\
\hline 30 & 92.9 & 84.5 & 4.2 & 0.6 & 18.0 & 0.4 \\
\hline 31 & 93.0 & 82.9 & 4.3 & -1.0 & 18.8 & 0.9 \\
\hline Jumlah & 2748.5 & 2599.8 & & & 428.9 & 193.1 \\
\hline Rata-rata & 88.7 & 83.9 & & & & \\
\hline
\end{tabular}

Dari tabel di atas, diperoleh hasil perhitungan untuk jumlah tingkat tekanan bunyi (SPL) pada sistem pembangkit suara akustik dengan efek surround sebagai berikut :

$$
\begin{aligned}
\sum F & =\left(F_{j, 1}+F_{j, 2}+F_{j, 3}\right) \\
& =(83,6+89,3+\cdots+93,0) \\
& =2.748,5 d B
\end{aligned}
$$

Hasil perhitungan untuk jumlah tingkat tekanan bunyi (SPL) tanpa efek surround diperoleh sebagai berikut :

$$
\begin{aligned}
\sum \mathrm{H} & =\left(\mathrm{H}_{\mathrm{j}, 1}+\mathrm{H}_{\mathrm{j}, 2}+\mathrm{H}_{\mathrm{j}, 3}\right) \\
& =(78,6+81,5+\cdots+82,9) \\
& =2.599,8 d B
\end{aligned}
$$

Hasil perhitungan untuk rata-rata tingkat tekanan bunyi (SPL) pada sistem pembangkit suara akustik dengan efek surround diperoleh sebagai berikut :

$$
\begin{aligned}
\overline{\mathrm{F}} & =\frac{\sum \mathrm{F}}{\mathrm{n}}=\frac{2.748,5}{31} \\
& =88,661 \mathrm{~dB}
\end{aligned}
$$

Hasil perhitungan untuk rata-rata tingkat tekanan bunyi (SPL) tanpa efek surround diperoleh sebagai berikut :

$$
\begin{aligned}
\bar{H} & =\frac{\sum H}{n}=\frac{2.599,8}{31} \\
& =83,865 \mathrm{~dB}
\end{aligned}
$$

Untuk standar deviasi dari tingkat tekanan bunyi pada sistem pembangkit suara akustik dengan efek surround diperoleh sebagai berikut :

$$
\begin{aligned}
& S_{F}=\sqrt{\frac{\sum\left(F_{j}-\bar{F}\right)^{2}}{n-1}} \\
& =\sqrt{\frac{(83,6-88,7)^{2}+\cdots+(93,0-88,7)^{2}}{31-1}} \\
& =3,78
\end{aligned}
$$

Untuk standar deviasi dari tingkat tekanan bunyi tanpa efek surround diperoleh sebagai berikut : 


$$
\begin{aligned}
& S_{H}=\sqrt{\frac{\sum\left(H_{j}-\bar{H}\right)^{2}}{n-1}} \\
& =\sqrt{\frac{(78,6-83,9)^{2}+\cdots+(82,9-83,9)^{2}}{31-1}} \\
& =2,54
\end{aligned}
$$

Selain standar deviasi, untuk menghitung distribusi " $t$ ", terlebih dahulu menghitung standar probabilitas dari tingkat tekanan bunyi pada sistem pembangkit suara akustik dengan efek surround dan tanpa efek surround yang diperoleh sebagai berikut :

$$
\begin{aligned}
& S_{P}=\sqrt{\frac{\left(n_{F}-1\right) S_{F}^{2}+\left(n_{2}-1\right) S_{H}^{2}}{n_{1}+n_{2}-2}} \\
& =\sqrt{\frac{(31-1) x(3,78)^{2}+(31-1) x(2,53)^{2}}{31+31-2}} \\
& =3,21
\end{aligned}
$$

Setelah diperoleh standar probabilitasnya, maka distribusi " $t$ " dapat dihitung dengan persamaan sebagai berikut :

$$
\begin{aligned}
t_{\text {hit }}= & \frac{\overline{\mathrm{F}}-\overline{\mathrm{H}}}{\mathrm{S}_{\mathrm{P}} \sqrt{\frac{1}{\mathrm{n}_{\mathrm{F}}}+\frac{1}{\mathrm{n}_{\mathrm{H}}}}} \\
= & \frac{88,6-83,8}{3,21 x \sqrt{\frac{1}{31}+\frac{1}{31}}} \\
& =5,87
\end{aligned}
$$

Dari daftar distribusi t student diperoleh bahwa :

Jika : $\alpha=0,05, \mathrm{df}=60$, maka $t_{\text {tabel }}=$ 2,000

Jika : $\alpha=0,01$, df $=60$, maka $t_{\text {tabel }}=$ 2,660
Untuk daerah penerimaan untuk $\mathrm{H}_{0}$ diterima, $\mathrm{H}_{1}$ ditolak

Jika : $-2,000<\mathrm{t}_{\text {hit }}<2,000$ pada $\alpha=0,05$

Jika : $-2,660<\mathrm{t}_{\text {hit }}<2,660$ pada $\alpha=0,01$

Berdasarkan hasil perhitungan distribusi $\mathrm{t}$ untuk tingkat tekanan bunyi (SPL) antara sistem pembangkit suara akustik dengan efek surround dengan tanpa efek surround pada jarak 1 meter diperoleh:

$t_{\text {hit }}>2,000$ pada $\alpha=0,05$

$t_{\text {hit }}>2,660$ pada $\alpha=0,01$

Dari hasil distribusi $\mathrm{t}$ tersebut dapat disimpulkan bahwa nilai $t_{\text {hit }}$ lebih besar dari nilai $\mathrm{t}$ tabel, maka cukup bukti bagi kita untuk melakukan penolakan terhadap $\mathrm{H}_{0}$ sehingga $\mathrm{H}_{1}$ diterima. Ditolaknya $\mathrm{H}_{0}$ sehingga $\mathrm{H}_{1}$ diterima, maka dapat disimpulkan bahwa ada perbedaan antara sistem pembangkit suara akustik dengan efek surround dan tanpa efek surround.

Grafik Hasil Pengujian Distribusi “T" Pada Jarak 1 Meter Sampai Dengan 10 Meter Hasil perhitungan data tingkat tekanan bunyi (SPL) pada jarak 1 meter sampai dengan 10 meter menggunakan uji statistik dengan distribusi " $t$ " ditunjukkan pada Gambar 3.

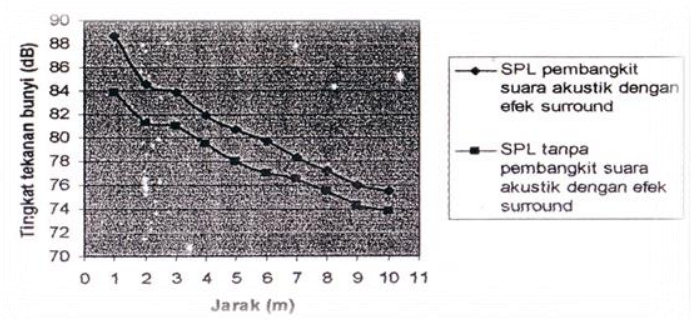

Sumber : Hasil Pengolahan Data

Gambar 3. Grafik Hubungan antara Tingkat Tekanan Bunyi (SPL) dan Jarak Terhadap Sumber "A"

Gambar 3 merupakan grafik antara tingkat tekanan bunyi dengan sistem pembangkit 
suara akustik dengan efek surround dan tanpa efek surround yang dilakukan di dalam Auditorium Widya Sabha Universitas Udayana Bukit Jimbaran.

Gambar 3 menunjukkan grafik linier negatif, hal ini terjadi karena semakin jauh jarak pengukuran, maka tingkat tekanan bunyinya semakin rendah. Hasil ini sejalan dengan penelitian sebelumnya bahwa secara umum daerah disekitar mesin diesel (sumber bunyi) adalah daerah dengan tingkat tekanan bunyi (kebisingan) paling tinggi kemudian menurun tiap perubahan jarak 1 meter dari mesin diesel dengan tingkat penurunan yang beragam baik sebelum maupun sesudah penggunaan penyungkup (enclosure) [2].

Penelitian ini juga menunjukkan bahwa tingkat tekanan bunyi yang dihasilkan sistem pembangkit suara akustik dengan efek surround dan tanpa efek surround berada di skala $60 \mathrm{~dB}$ sampai dengan 90 $\mathrm{dB}$, angka tersebut masih dibawah ambang rasa sakit pada skala $130 \mathrm{~dB}$. Hasil ini sejalan dengan penelitian sebelumnya yang dilakukan oleh [1] di kampus Indralaya menyatakan bahwa tingkat tekanan bunyi (kebisingan) yang terukur berada diantara $50-84 \mathrm{~dB}$.

Penelitian [6] mengkategorikan tingkat tekanan bunyi antara ambang yang dapat didengar pada skala $0 \mathrm{~dB}$ hingga jauh diatas ambang rasa sakit pada skala $130 \mathrm{~dB}$ yang ditunjukkan seperti berikut:

\begin{tabular}{|l|l|c|}
\hline Sumber / keadaan & \multicolumn{1}{|c|}{$\begin{array}{c}\text { Intensitas I } \\
(\mathbf{W} / \mathbf{m} 2)\end{array}$} & $\begin{array}{c}\text { Tingkat Intensitas IL } \\
(\mathrm{dB})\end{array}$ \\
\hline Ambang rasa sakit & 10 & 130 \\
\hline $\begin{array}{l}\text { Dekat pesawat jet yang } \\
\text { tinggal landas }\end{array}$ & 1 & 120 \\
\hline Mesin pengeling & 0,1 & 110 \\
\hline Palu pneumatik & 0,01 & 100 \\
\hline Truk diesel pada jarak $15 \mathrm{~m}$ & 0,001 & 90 \\
\hline Teriakan pada jarak I $\mathrm{m}$ & $0,0.001$ & 80 \\
\hline Kantor yang sibuk & $0,00.001$ & 70 \\
\hline Bercakap-cakap pada jarak I m & $0,000.001$ & 60 \\
\hline $\begin{array}{l}\text { Daerah urban yang tenang } \\
\text { pada siang hari }\end{array}$ & $0,0.000 .001$ & 50 \\
\hline $\begin{array}{l}\text { Daerah urban yarig tenang pada } \\
\text { malam hari }\end{array}$ & $0,00.000 .001$ & 40 \\
\hline $\begin{array}{l}\text { Daerah suburban tenang } \\
\text { pada malam hari }\end{array}$ & $0,000.000 .001$ & 30 \\
\hline Dacrah pedalaman yang tenang & $0,0.000 .000 .001$ & 20 \\
\hline Nafas manusia & $0,00.000 .000 .001$ & 10 \\
\hline Ambang pendengaran & $0,000,000.000 .001$ & 0 \\
\hline & & Sumber : $[6]$ \\
\hline
\end{tabular}

\section{Gambar 4. Kriteria Tingkat Tekanan Bunyi pada Beberapa Sumber Bunyi}

Selain itu, dari setiap jarak yang diamati, terjadi perbedaan tingkat tekanan bunyi dimana tingkat tekanan bunyi dengan sistem pembangkit suara akustik dengan efek surround lebih tinggi dibandingkan dengan tanpa efek surround.

\section{SIMPULAN}

Berdasarkan hasil pengujian yang dilakukan, diperoleh beberapa kesimpulan sebagai berikut :

1. Dari data perhitungan statistik dengan menggunakan distribusi " $t$ " didapatkan tingkat tekanan bunyi (SPL) dengan sistem pembangkit suara akustik dengan efek surround lebih tinggi dibandingkan tanpa efek surround pada jarak 1 meter sampai dengan 10 meter.

2. Penelitian ini menunjukkan bahwa semakin jauh jarak dari sumber bunyi, maka tingkat tekanan bunyi yang didapatkan semakin rendah.

3. Penelitian ini juga menunjukkan bahwa tingkat tekanan bunyi yang dihasilkan sistem pembangkit suara akustik dengan efek surround dan tanpa efek surround berada di skala $60 \mathrm{~dB}$ sampai dengan $90 \mathrm{~dB}$, angka tersebut masih dibawah ambang rasa sakit pada skala $120 \mathrm{~dB}$. 


\section{DAFTAR PUSTAKA}

[1] Adnan, Yulinar., The Measurement of Noise Level Intensity at Indralaya Campus, Jurnal Penelitian Sains Universitas Indralaya, No. 19 pp. 6-15, 2006.

[2] Ahmad Su'udi., Reduksi Bising Motor Diesel Menggunakan Partial Enclosure, Jurnal Mechanical, Vol. 1, No. 1, Maret 2010.

[3] Bachri, Affan., Laksono, Arief. B., Hakim, Arif. Lukman., Rancang Bangun Sistem Audio Surround Processor Berbasis IC UPC1891 $A C Y$, Jurnal Program Studi Teknik Elektro JE-Unisia, 2015.

[4] Halliday, D., Resnick, R., dan Walker, J., Physics, $7^{\text {th }}$ Extended Edition, John Wiley \& Sons, 2005, Terjemahan oleh Tim Pengajar Fisika ITB, Fisika Dasar, Edisi Ketujuh, Jilid 1, Erlangga, Jakarta, 2010.

[5] Juningin., Kajian Variasi Jarak Antar Penghalang Suara yang dihasilkan oleh Sumber Suara, Karya Tulis Ilmiah, Jurusan Fisika, FMIPA, Universitas PGRI Palembang, 2012.
[6] Lea Prasetyo, Akustik. Karya Tulis Ilmiah, Jurusan Fisika, FMIPA ITS, 2003.

[7] Mandagi, Albert., Rancang Bangun Alat Pembangkit Efek Surround dengan IC Bucket Brigade Device (BBD) MN 3008, JETri, Vol. 12, No. 2, pp 99-109, 2015

[8] M. Sobirin., Ikhwan Elfitri., Perancangan dan Analisis Kinerja Pengkodean Audio Multichannel dengan Metode Close Loop, Jurnal Nasional Teknik Elektro ST3 Telkom Purwokerto, Vol. 3, No. 2, 2014.

[9] Schenk C., Decker C., Gruber H., Noise : Identification and Evaluation of Hazard, Germany, 2008.

[10] Suyanto, Hery., Windaryoto., Perhitungan Intensitas Level pada Beberapa Sumber Bunyi dengan Metode Selisih Penjumlahan $d B$, Karya Tulis Ilmiah, Jurusan Fisika FMIPA, Universitas Udayana, 2017. 